\title{
Early lung cancer detection: the role of primary care
}

Lung cancer remains one of the most significant challenges for health care in the UK. Despite advances in treatment, survival from this disease in the UK has improved very little, and still compares unfavourably with survival rates in the USA and in much of Europe. If we are to tackle this disease more effectively it is likely that we will need an approach which combines primary prevention, early detection strategies, and improved treatments.

In this issue of the Primary Care Respiratory Journal Read et al. review current evidence on early detection of lung cancer [1]. It's not an overly optimistic picture; luns canced yeically presents late in its collse, and che symptoms at an earty siage are Gifficult to detect. While new diagrostic strategies are ging, we still lack the evidence to screen for lung cancer in the population. As Journal readers will be aware, general practitioners (GPs) face considerable challenges in making a diagnosis of lung cancer symptoms are generally non-specific, and can be attributed to many other common causes such as chronic bronchitis or asthma. Primary care has the potential to influence early detection in four major areas: primary prevention (principally smoking cessation); encouragement of early presentation; early symptom-based diagnosis; and influencing future possible screening strategies.

\section{Primary prevention}

Tobacco smoking is the most important risk factor for the development of lung cancer. It causes $90 \%$ of lung cancers in the UK [2]. Although the prevalence of smoking has fallen over the last couple of decades [3], approximately $25 \%$ of adults are still smokers and about 450 children start smoking each day in the UK [4].

Primary care plays an important role in providing guidance and support to patients to stop smoking. GPs can, for example, reduce smoking rates by providing appropriate advice [5]. Furthermore, about $25 \%$ of lung cancers in never-smokers are associated with exposure to passive smoking [6]. Smoking bans in all enclosed spaces in Ireland and Scotland have proved sucres.iul, and can complement other effiprls from the public health and primary saie wurnorce.

\section{(a) \\ imininnising patient-related delay}

Although there is no direct evidence that early diagnosis would reduce mortality from lung cancer, there is a strong possibility that a shift away from the current pattern of late presentation, with a corresponding increase in potentially curative treatments such as lung resection, could impact favourably on survival [7]. Hence, reductions in delay have become a policy priority [8].

Relatively little is known about the reasons why patients delay consulting with their symptoms. It appears that individuals frequently fail to recognise symptoms that they've experienced over many months prior to their eventual diagnosis as being serious or 'warranting medical attention' $[9,10]$; symptoms, even when severe, are typically attributed to more common, everyday causes. There is sometimes a 'nihilistic' attitude to lung cancer - there is a strong perception in the community that lung cancer is 'incurable' with little point in trying to identify it early [11]. These attitudes imply an important educational role for primary care; patients need to be 
encouraged not to ignore symptoms of potential significance.

\section{Early detection based on symptoms}

The majority of lung cancer patients in the UK are diagnosed following presentation in primary care [12]. Typically, though, diagnosis is made through a variety of other routes as well: these include accident and emergency departments and hospital inpatient referrals [10]. The symptoms of lung cancer pose significant diagnostic challenges for primary care teams; it is very difficult to distinguish between those respiratory symptoms which carry increased risk of lung cancer and those which do not. The symptoms of lung cancer such as cough, haemoptysis and weight loss, are common in primary care populations, and the average GP will see less than two cases of lung cancer per year. In addition, many symptoms are experienced by patients in the months leading up to diagnosis and they are often non-specific. Even for an alarming symptom such as haemoptysis, which is commonly reported as a first symptom by lung cancer patients [13], there are several common causes including chest infections. Other symptoms such as weight loss, cough, dyspnoea and cRest pain, while important componems OChe nistory, are even less sperific ior liung caricer [14]

Whil s (m) prouress has bsen mavion. att.ching predictive values to sympconis, and groups of symptoms, as a guide to decision making [15], we are some way off having precise diagnostic algorithms to guide investigation and referral decisions with specific patients. Most guidelines highlight the importance of change in patients' symptoms [16]. Existing cancer referral guidelines typically recommend basic investigations and referral for persistent and unexplained symptoms [17-19] - but much still relies on clinical judgement. Further, despite the availability of guidelines, there is potential to reduce delays in referral from primary to secondary care [20,21], and this is an important ongoing challenge.

\section{Screening for lung cancer}

As Spiro and colleagues indicate [1], there is renewed interest in the prospect of early detection of lung cancer through screening. More will be known about the potential of spiral CT scanning in early, asymptomatic diagnosis, once major screening trials have reported [22]. If mortality reductions are identified, it is likely that screening will need to be part of a wider range of strategies. Further, in common with other forms of screening, primary care will continue to play a vital role in promoting uptake and providing information.

\section{Conclusion}

Primary care continues to have an important gatekeeper role in lung cancer investigation and diagnosis, and needs to help co-ordinate the complex diagnostic pathway for this disease. Importantly, it is necessary to maintain a high index of suspicion in high-risk patients, and to monitor symptom changes (such as extra symptoms, changes in frequency or severity etc) in patients with existing lung disease. This way, delays related to primary care can be minimised.

There is also an important research agenda; lung cancer has, in the past, had relatively little research investment [23]. This has prompted the National Cancer Research Institute to undertake a major strategic review of lung cancer research and the report has now befn published [24]. The report identifies ths rearg for targeted funding and new prioride: for research investment, and is very Welcone indeed. In their review [1], Spiro et al. describe a rew to $r$ al funded by Cancer Research UF, Which witi examine the effect of a surveillance strategy comprising sputum cytology/cytometry, annual CT scans and fluorescence bronchoscopy in bringing forward the time of diagnosis in a highrisk population. While mortality reductions need to be demonstrated in screening trials, the ability of a testing regime to bring about earlier diagnosis is, of course, a prerequisite. It is vital that these kinds of studies progress, ideally in tandem with trials of primary prevention and early symptombased diagnosis.

Hopefully in the near future we will have the evidence to effect strategies which can make an impact on survival - whether through smoking cessation, uptake of screening, or astute, early diagnosis, primary care will have a vital role in these strategies.

\section{References}

[1] Read C, et al. Early Lung Cancer: screening and detection. Prim Care Resp J 2006;15(6):332-6, doi:10.1016/j.pcrj.2006.09.003.

[2] International Agency for Research on Cancer. IARC Monographs on the evaluation of carcinogenic risks to humans: tobacco smoke and involuntary smoking, Vol 83. Lyon: IARC Press; 2004. 
[3] CancerStats Monograph. Chapter on Lung cancer and smoking - UK. Cancer Research UK, April 2004.

[4] Peterson S, Peto V. Smoking statistics 2004. London: British Heart Foundation; 2004.

[5] Ashenden R, Silagy C, Weller D. A systematic review of the effectiveness of promoting lifestyle change in general practice. Fam Pract 1997;14:160-76.

[6] Alberg AJ, Samet JM. Epidemiology of Lung Cancer. Chest 2003;123:21-49.

[7] Moody A, Muers M, Forman D. Delays in managing lung cancer. Thorax 2004;59:1-3.

[8] The NHS Cancer Plan: a plan for investment, a plan for reform. Department of Health 2000.

[9] Corner J, Hopkinson J, Roffe L. Experience of health changes and reasons for delay in seeking care: A UK study of the months prior to the diagnosis of lung cancer. Soc Sci Med 2005:1381-91.

[10] Corner J, Hopkinson J, Fitzsimmons D, et al. Is late diagnosis of lung cancer inevitable? Interview study of patients' recollections of symptoms before diagnosis. Thorax 2005;60:314-9.

[11] Bleehan NM. Lung cancer-Still a long road ahead. British Journal of Cancer 1990;61:493-4.

[12] Melling PP, Hatfield AC, Muers MF, et al. Lung cancer referral patterns in the former Yorkshire region in the UK. British Journal of Cancer 2002;86:36-42.

[13] Hamilton W, Sharp D. Diagnosis of lung cancer in primary care: a structured review. Family Practice 2004;21:60511.

[14] Hannay DR. The Symptom Iceberg: A Study of Community Health. London: Routledge \& Kegan Paul; 1979.

[15] Hamilton W, Peters TJ, Round A, et al. What are the clinical features of lung cancer before the diagnosis is made? A population based case-control studv. Thor 2005;60:1059-65.

[16] Kvale PA. Chronic côush cùe in L ing tumours: ACCP evidence-basen (ihical practice guidelines. (1) $2006 ; 1: 9: 1<7-3.5$

[17] Referral Guidelines for Susp cted Cancer. London: Department of Health; 2000. http://www.dh.gov.uk/Policy
AndGuidance/HealthAndSocialCareTopics/Cancer/Cancer Generallnfo/fs/en?CONTENT_ID=4066665\&chk=5z4D86.

[18] Lung cancer: diagnosis and treatment. London: National Institute for Health and Clinical Excellence; 2005.http: / / www. nice.org.uk/page. aspx?o=244008.

[19] Scottish Referral Guidelines for Suspected Cancer. London: Scottish Executive; 2002. http://www.scotland.gov. uk/Publications/2002/05/14862/5419.

[20] Billings JS, Wells FC. Delays in the diagnosis and surgical treatment of lung cancer. Thorax 1996;51:903-6.

[21] Bowen EF, Rayner CJF. Patient and GP led delays in the recognition of symptoms suggestive of lung cancer. Lung Cancer 2002;37:227-8.

[22] Oken MM, Marcus PM, Hu P, et al. Baseline chest radiograph for lung cancer detection in the randomized Prostate, Lung, Colorectal and Ovarian Cancer Screening Trial. J Natl Cancer Inst 2005;97:1832-9.

[23] National Cancer Research Institute. Strategic Analysis 2002 An overview of Cancer Research in the UK. NCRI; 2000.

[24] National Cancer Research Institute. Lung Cancer Research in the UK: Report of the NCRI strategic Planing Group on Lung Cancer. 2006.

\section{David Weller*}

Professor of General Practice

Christine Campbell

Research Fellow

Division of Commu fity Hedul Siences, University of Ecilinengh, 20 west Richmond St., HICE AlEdinburgh EH10 5PF, Scotland, UK *Correspondir's outhor. Tel.: +44 1316509518 ; fax: +441316509519.

E-mail address: david.weller@ed.ac.uk (D. Weller)

25 September 2006

Available online at www.sciencedirect.com

ScienceDirect 